\title{
Biomarker in insulin resistant and its complication.
}

\author{
N. Banu ${ }^{1}$, K.S. Elango ${ }^{2,3}$, A. Rajendran ${ }^{3}$ \\ ${ }^{1}$ Assistant Professor, Bharathi Women's College (Autonomous), Chennai, India \\ ${ }^{2}$ Research Scholar, Vel's Institute of Science, Technology \& Advanced Studies, Pallavaram, Chennai, India \\ ${ }^{3}$ Clinical Laboratory, D.A.E. Hospital, Department of Atomic Energy, Kalpakkam, Chennai, India
}

\begin{abstract}
Aims: In Type 2 diabetes, Insulin resistant leads microvascular and macrovascular complication. Early finding prevents from this complication and it is a challenging task. A decade research shows adiponectin may be a marker for insulin resistant. Increasing the level of adiponectin prevent the progression of insulin resistant (IR). In this research we are striving adiponectin as a biomarker for insulin resistant also associating the correlation with lipid parameter in the South Indian population.

Methods: 30 Type 2 Diabetic patients, 20 Controls were studied. Fasting serum sample were used to measure Adiponectin, Insulin, Lipid parameters (Cholesterol, Triglyceride, HDL) Fasting plasma sample were used to measure Glucose. Anthropometric data including height, weight, BMI and were measured using a standard technique.

Results: Wilcoxon signed rank test shows the significant variation between Adiponectin and other analytes. The reduction of mean adiponectin value observed in patient's sample compared to control sample. Insignificant negative correlation between Fasting blood sugar (FBS) and Adiponectin also negative correlation between Adiponectin and Insulin observed. In lipid parameters, significant positive correlation between Adiponectin and HDL and significant negative correlation between Adiponectin and triglyceride observed.

Conclusion: Adiponectin might be a prediction for biomarker in Type 2 diabetes associated insulin resistant among South Indians also if test has been done with the high specificity and sensitivity ELISA kit it will improve the insignificant correlation to significant correlation.
\end{abstract}

Keywords: Adiponectin, Insulin resistant, Wilcoxon signed rank, Type2 Diabetes.

Accepted on July 23, 2018

\section{Introduction}

$\beta$ cell dysfunction is one of the major causes for insulin resistance in type 2 diabetes, also in some cases longstanding stress causes the elevation of cortisol, higher level of this hormone damages the $\beta$ cell by the way decreases insulin production and increases the insulin resistant [1]. Prolonged exposure of high level of fatty acids accumulates in the muscle and liver, causes the inhibition of glucose to enter in both tissues, in response more amount of insulin produced (Hyperinsulinemia) to unlock the cell for utilisation of glucose. Frequent and longstanding of this type of mechanism end in apoptosis of islet cell also no more overproducing insulin to meet the requirement of muscle and liver which is also causative for insulin resistant [2,3]. More researches on central obesity reports, visceral lipid deposits are increased and the abdominal subcutaneous adipose tissue depot is decreased, in type 2 associated insulin resistance in Asian Indians. Recent researches emphasised the involvement of adiponectin, one of the adipokines released from adipose tissue that regulates the metabolism of lipids and glucose also increases the insulin sensitivity [4,5]. In this research we are striving to find out the adiponectin as a Biomarker for insulin resistant in type 2 diabetes among South Indians, also finding the correlation between the lipid analytes. Early finding of insulin resistant through a biomarker will help to prevent from micro vascular and macro vascular complications [6].

\section{Material and Methods}

The study has been conducted at D.A.E. Township, Kalpakkam, Kancheepuram District, Tamilnadu, India as a Patient-Control study. Age range from 40 to 60 years including both genders categorised Type 2 diabetes (Patients samples) and Non-diabetes (Control samples). Written informed consent was obtained from each participant before commencement of the study.

The sample included with 20 samples normal healthy individuals, and the 30 samples of known Type 2 diabetes. Before blood collection Individuals Age, Sex, Height, Weight noted. BMI was calculated using Height and Weight 
measurement [7]. 10-12 hours overnight fasting instructed for both the subjects. After overnight fasting Venous blood drawn from individuals and $2 \mathrm{ml}$ transferred in sodium fluoride $/ \mathrm{Na} 2$ EDTA anticoagulated tubes for fasting blood glucose estimation, remaining $6 \mathrm{ml}$ blood was transferred in plain tubes (without anticoagulant) for estimation of serum fasting insulin, serum adiponectin, HDL and LDL. All the samples were centrifuged at $2000 \mathrm{rpm}$ for 10 minutes, and the fasting blood glucose estimation done by glucose oxidase/peroxidase (GOD/ POD) method, Serum insulin measured by chemiluminescence method, Serum Triglyceride measured by enzymatic method i.e. GPO - PAP (Glycerol phosphate oxidase-peroxidaseamidopyrine method), Serum HDL measured by Cholesterol Esterase, Peroxidase end point method [10, 11]. Serum adiponectin measured using DBC (Diagnostics Biochem Canada) ELISA Kit [8,9].

\section{Statistical analysis}

SPSS (version 20) statistical software was used for analyses. Data were also categorized according to patients and control fasting serum insulin, serum HDL, LDL, BMI, fasting plasma glucose and were evaluated using a Pearson's correlation coefficient analysis. Comparisons of parameters in patients and control were performed with a significance level of $\mathrm{p}<0.05$ $[14,15]$.

\section{Results and Discussion}

A significant increase of insulin, and highly significant increase in fasting blood glucose in diabetic (patient sample) compared with control samples confirms the selected patients are insulin resistant. The low mean concentration value of adiponectin, HDL in patient's sample compared with control sample observed. In contrast, the mean concentration of LDL decreased in patient sample, this may be due to patients on regular medication for lipid reducing drugs (Table 1).

Table 1. Comparison of parameters in control and patients samples.

\begin{tabular}{llll}
\hline Parameter & Control & Patients & P Value \\
\hline Age & $46.55 \pm 5.8$ & $47.9 \pm 5.8$ & 0.428 \\
\hline BMI $(\mathrm{Kg} / \mathrm{m} 2)$ & $24.75 \pm 3.6$ & $25.03 \pm 3.5$ & 0.786 \\
\hline ADIPONECTIN $(\mu \mathrm{g} / \mathrm{mL})$ & $4.12 \pm 2.2$ & $3.95 \pm 2.2$ & 0.8 \\
\hline FBS $(\mathrm{Mg} / \mathrm{dl})$ & $103.35 \pm 12.5$ & $192.06 \pm 72.6$ & $<0.0001$ ** \\
\hline INSULIN $(\mu l \mathrm{l} / \mathrm{Ml})$ & $8.72 \pm 3.2$ & $13.86 \pm 9.6$ & $0.026 *$ \\
\hline HDL $(\mathrm{Mg} / \mathrm{dl})$ & $41.3 \pm 13.6$ & $35.8 \pm 6.9$ & 0.065 \\
\hline LDL $(\mathrm{Mg} / \mathrm{dl})$ & $110.9 \pm 38.02$ & $94.3 \pm 28.03$ & 0.082 \\
\hline
\end{tabular}

*significant $(P<0.05){ }^{* *}$ Highly significant $(P<0.0001)$

In respect of correlation studies, Insignificant negative correlation of adiponectin $(\mathrm{r}=-0.014)$ with fasting blood glucose, and negative correlation with fasting insulin $(\mathrm{r}=-0.165)$ were observed. Increasing the Sample size may improve the significance of correlation [22].

One of the Type 2 associated complication is atherosclerosis [16]. Adiponectin shows highly significant $(\mathrm{p}<0.01)$ moderate positive correlation with HDL $(\mathrm{r}=0.479)$, and significant $(\mathrm{p}<0.05)$ moderate negative correlation with Triglyceride (risk factor for CVD) ( $\mathrm{r}=-0.314)$ [21] (Table 2).

Table 2. Correlation of adiponectin (adipo) with fasting blood sugar (fbs), insulin, cholesterol, high density lipoprotein (hdl), triglyceride (tgl).

\begin{tabular}{|c|c|c|c|c|c|c|c|}
\hline \multicolumn{8}{|c|}{ Correlations } \\
\hline & & FBS & Insulin & ADIPO & CHOL & HDL & TGL \\
\hline & Pearson Correlation & 1 & -0.007 & -0.014 & -0.256 & -0.239 & 0.039 \\
\hline \multirow[t]{3}{*}{ FBS } & Sig. (2-tailed) & & 0.961 & 0.921 & 0.072 & 0.095 & 0.79 \\
\hline & $\mathrm{N}$ & 50 & 50 & 50 & 50 & 50 & 50 \\
\hline & Pearson Correlation & -0.007 & 1 & -0.165 & -0.081 & -0.196 & 0.056 \\
\hline \multirow[t]{3}{*}{ Insulin } & Sig. (2-tailed) & 0.961 & & 0.252 & 0.576 & 0.173 & 0.697 \\
\hline & $\mathrm{N}$ & 50 & 50 & 50 & 50 & 50 & 50 \\
\hline & Pearson Correlation & -0.014 & -0.165 & 1 & 0.185 & $.479^{* *}$ & $-.314^{*}$ \\
\hline \multirow[t]{3}{*}{ ADIPO } & Sig. (2-tailed) & 0.921 & 0.252 & & 0.198 & 0 & 0.027 \\
\hline & $\mathrm{N}$ & 50 & 50 & 50 & 50 & 50 & 50 \\
\hline & Pearson Correlation & -0.256 & -0.081 & 0.185 & 1 & $.359^{*}$ & 0.116 \\
\hline \multirow[t]{2}{*}{$\mathrm{CHOL}$} & Sig. (2-tailed) & 0.072 & 0.576 & 0.198 & & 0.011 & 0.422 \\
\hline & $\mathrm{N}$ & 50 & 50 & 50 & 50 & 50 & 50 \\
\hline $\mathrm{HDL}$ & Pearson Correlation & -0.239 & -0.196 & $.479^{* *}$ & $.359^{*}$ & 1 & $-.379^{* *}$ \\
\hline
\end{tabular}




\begin{tabular}{|c|c|c|c|c|c|c|c|}
\hline & Sig. (2-tailed) & 0.095 & 0.173 & 0 & 0.011 & & 0.007 \\
\hline & $N$ & 50 & 50 & 50 & 50 & 50 & 50 \\
\hline \multirow{3}{*}{ TGL } & Pearson Correlation & 0.039 & 0.056 & $-.314^{*}$ & 0.116 & $-.379^{* *}$ & 1 \\
\hline & Sig. (2-tailed) & 0.79 & 0.697 & 0.027 & 0.422 & 0.007 & \\
\hline & $\mathrm{N}$ & 50 & 50 & 50 & 50 & 50 & 50 \\
\hline
\end{tabular}

${ }^{* *}$ Correlation is significant at the 0.01 level (2-tailed).

${ }^{*}$ Correlation is significant at the 0.05 level (2-tailed).

Decade research shows that Asian Indians have more insulin resistance (IR) than other ethnicity. Higher level of BMI ( $>25)$, fasting blood sugar, fasting insulin are some of the causes for IR, but in South Indians insulin resistant observed due to central obesity [17]. Adiponectin is a protein encoded by ADIPOQ gene, secreted from adipose tissue, involves in glucose and lipid level regulation

In the present study, the adiponectin in diabetic patients had a lower mean value than control samples, and the patient's adiponectin positively associated with HDL, both of these observations same like previous studies by Leena chand, 2016 [19]. Adiponectin level can be linked to whole-body insulin sensitivity, and hypoadiponectinemia can cause endothelial dysfunction by decreasing insulin sensitivity, also it may be directly linked to early atherosclerotic vascular damage and a subsequent endothelial dysfunction [18].

Comparing patients sample fasting blood sugar mean value with control sample mean value and patient sample fasting insulin mean value with control sample mean value shows higher and statistically significant. These observations seen same as previous studies by Julian Esparza-Romero et. al., 2010 [20].

Significance difference between the Adiponectin and other parameter analysed using Wilcoxon Signed Rank Test (Table 3 ). The result shows there is significant difference between the decreasing level of adiponectin with increasing level of fasting blood sugar level $[12,13]$ (Table 4).

Table 3. Wilcoxon signed rank test.

\begin{tabular}{llllll}
\hline Test Statistics $^{\mathrm{a}}$ & ADIPO-FBS & ADIPO-INSULIN & ADIPO-BMI & ADIPO-CHOL & ADIPO-HDL \\
\hline Z & $-6.154^{\mathrm{b}}$ & $-5.662^{\mathrm{b}}$ & $-6.154^{\mathrm{b}}$ & $-6.154^{\mathrm{b}}$ & $-6.154^{\mathrm{b}}$ \\
\hline Asymp. Sig. (2-tailed) & 0 & 0 & 0 & 0 & 0 \\
\hline a. Wilcoxon Signed Rank Test b. Based on Positive Ranks & & & 0 \\
\hline
\end{tabular}

Table 4. Wilcoxon signed rank test. Mean Rank and Sum of ranks.

\begin{tabular}{|c|c|c|c|c|}
\hline Ranks & & & & \\
\hline & & $\mathbf{N}$ & Mean Rank & Sum of Ranks \\
\hline \multirow{4}{*}{ ADIPO - FBS } & Negative Ranks & $50 a$ & 25.5 & 1275 \\
\hline & Positive Ranks & $\mathrm{Ob}$ & 0 & 0 \\
\hline & Ties & 0c & & \\
\hline & Total & 50 & & \\
\hline \multirow{4}{*}{ ADIPO - Insulin } & Negative Ranks & $47 d$ & 26.04 & 1224 \\
\hline & Positive Ranks & $3 e$ & 17 & 51 \\
\hline & Ties & Of & & \\
\hline & Total & 50 & & \\
\hline \multirow{2}{*}{ ADIPO - BMI } & Negative Ranks & $50 \mathrm{~g}$ & 25.5 & 1275 \\
\hline & Positive Ranks & Oh & 0 & 0 \\
\hline
\end{tabular}




\begin{tabular}{|c|c|c|c|c|}
\hline & \\
\hline & Ties & $0 \mathrm{i}$ & & \\
\hline & Total & 50 & & \\
\hline \multirow{4}{*}{ ADIPO - CHOL } & Negative Ranks & $50 \mathrm{j}$ & 25.5 & 1275 \\
\hline & Positive Ranks & Ok & 0 & 0 \\
\hline & Ties & 이 & & \\
\hline & Total & 50 & & \\
\hline \multirow{4}{*}{ ADIPO - HDL } & Negative Ranks & $50 \mathrm{~m}$ & 25.5 & 1275 \\
\hline & Positive Ranks & On & 0 & 0 \\
\hline & Ties & 0o & & \\
\hline & Total & 50 & & \\
\hline \multirow{4}{*}{ ADIPO - TGL } & Negative Ranks & $50 p$ & 25.5 & 1275 \\
\hline & Positive Ranks & $0 q$ & 0 & 0 \\
\hline & Ties & or & & \\
\hline & Total & 50 & & \\
\hline
\end{tabular}

a. ADIPO<FBS; b. ADIPO>FBS; c. ADIPO = FB; d. ADIPO<Insulin; e. ADIPO>Insulin; f. ADIPO = Insulin; g. ADIPO<BMI; h. ADIPO>BMI; i. ADIPO=BMI; j. ADIPO<CHOL; k. ADIPO>CHOL; I. ADIPO=CHOL; m. ADIPO<HDL; n. ADIPO>HDL; o. ADIPO=HDL; p. ADIPO<TGL; q. ADIPO>TGL; r. ADIPO=TGL

\section{Conclusion}

Serum Adiponectin level decreases with insulin resistance, also decreases in type 2 associated complications (Low level HDL, and High level Triglyceride). These observations were well correlated and adiponectin can be used as a biomarker in Type 2 associated insulin resistant and its complication with the high sensitivity and high specificity kit.

\section{Funding}

This study did not receive funding.

\section{Conflicts of interest}

The authors declare no conflicts of interest.

\section{Guarantor statement}

Mr. K.S. Elango is the guarantor of this work and, as such, had full access to all the data in the study and takes responsibility for the integrity of the data and the accuracy of the data analysis.

\section{References}

1. Taylor R. Insulin resistance and type 2 diabetes. Diabetes 2012; 61: 778-779.

2. Tripathy D, Eriksson KF, Orho-Melander M, Fredriksson J, Ahlqvist G, Groop L. Parallel manifestation of insulin resistance and beta cell decompensation is compatible with a common defect in Type 2 diabetes. Diabetologia 2004; 47: 782-793.
3. Lebovitz HE, Banerji MA. Point: visceral adiposity is causally related to insulin resistance. Diabetes care. 2005; 28: 2322-2325.

4. Garg A. Regional adiposity and insulin resistance. J Clin Endocrinol Metabol 2004; 89: 4206-4210.

5. Yeow TP, Pacini G, Tura A, Hor CP, Lim SL, Tan FH, Tong CV, Hong JY, Zain FM, Holst JJ, Mohamud WN. Preserved glucagon-like peptide-1 responses to oral glucose, but reduced incretin effect, insulin secretion and sensitivity in young Asians with type 2 diabetes mellitus. BMJ Open Diabetes Res Care 2017; 5: e000352.

6. Snehalatha C, Mukesh B, Simon M, Viswanathan V, Haffner SM, Ramachandran A. Plasma adiponectin is an independent predictor of type 2 diabetes in Asian Indians. Diabetes care 2003; 26: 3226-3229.

7. Mamaghani F, Zarghami N, Maleki MJ, PourhassanMoghaddam M, Hosseinpanah F. Variation of adiponectin levels in normal and obese subjects: possible correlation with lipid profiles. Int J Endocrinol Metabol 2009; 7: 170-178.

8. Robinson K, Prins J, Venkatesh B. Clinical review: adiponectin biology and its role in inflammation and critical illness. Critical Care. 2011; 15: 221.

9. Shehzad A, Iqbal W, Shehzad O, Lee YS. Adiponectin: regulation of its production and its role in human diseases. Hormones 2012; 11: 8-20.

10. ATP III AA. Glance. Quick Desk Reference. Book ATP III At-A-Glance: Quick Desk Reference (Editor ed.^ eds.). City: National Institutes of Health. 2001.

11. Francis Sahngun Nahm. Nonparametric statistical tests for the continuous data: the basic concept and the practical use. Korean J Anesthesiol 2016; 69: 8-14. 
12. Harris JE, Boushey C, Bruemmer B, Archer SL. Publishing nutrition research: a review of nonparametric methods, part 3. J American Dietetic Assoc 2008; 108: 1488-1496.

13. Gardner MJ, Altman DG. Statistics with confidence: confidence intervals and statistical guidelines. British Med J 2000 .

14. Campbell MJ, Machin D, Walters SJ. Medical statistics: a textbook for the health sciences. John Wiley \& Sons 2010.

15. Khoo CM, Sairazi S, Taslim S, Gardner D, Wu Y, Lee J, van Dam RM, Tai ES. Ethnicity modifies the relationships of insulin resistance, inflammation, and adiponectin with obesity in a multiethnic Asian population. Diabetes care 2011; 34: 1120-1126.

16. Duncan BB, Schmidt MI, Pankow JS, Bang H, Couper D, Ballantyne CM, Hoogeveen RC, Heiss G. Adiponectin and the development of type 2 diabetes: the atherosclerosis risk in communities study. Diabetes 2004; 53: 2473-2478.

17. Shimabukuro M, Higa N, Asahi T, Oshiro Y, Takasu N, Tagawa T, Ueda S, Shimomura I, Funahashi T, Matsuzawa Y. Hypoadiponectinemia is closely linked to endothelial dysfunction in man. J Clin Endocrinol Metabol 2003; 88: 3236-3240.
18. Chand L, Silambanan S. SERUM ADIPONECTIN LEVEL IN OBESE AND NON OBESE TYPE 2 DIABETES MELLITUS. Int J Clin and Biomed Res 2016 28; 2: 8-12.

19. Esparza-Romero J, Valencia ME, Martinez ME, Ravussin E, Schulz LO, Bennett PH. Differences in insulin resistance in Mexican and US Pima Indians with normal glucose tolerance. J Clin Endocrinol Metabol 2010; 95: E358-E362.

20. Beatriz G, Talayero MD, Frank M, Sacks MD. The Role of Triglycerides in Atherosclerosis, Curr Cardiol Rep 2011; 13: 544-552.

21. Dahiru T. P-value, a true test of statistical significance? A cautionary note. An Ib Postgrad Med. 2008; 6: 21-26.

\section{*Correspondence to}

Elango KS

Department of Atomic Energy

Kalpakkam

Tamil Nadu

India 